\title{
Optimization of Stiffened Square Plate Topographically under Uniform distributed Pressure
}

\author{
U.N. Eman ${ }^{1, *}$, H.M.S. Firdaus ${ }^{1}$, M.Y. Halyani ${ }^{1}$, Zulhasnizam Hasan ${ }^{1}$, and R.F. Farhana ${ }^{2}$ \\ ${ }^{1}$ Faculty of Engineering Technology, Technical University of Malaysia, Melaka, Hang Tuah Jaya, \\ 76100, Durian Tunggal, Melaka, Malaysia. \\ ${ }^{2}$ Armag Oil \& Gas Academy, Kompleks Usahawan Terengganu, Kg. Kubang Jela, 21200 Kuala \\ Terengganu, Terengganu, Malaysia.
}

\begin{abstract}
The structure of stiffened plate is widely used in engineering since $19^{\text {th }}$ century and is currently used in many modern applications. When stiffened square plate was imposed to extremely high load, the thin plate structure will deform. This research is carried out to find the solution in optimizing the structure of stiffened square plate topographically. The structure of square plate is analysed by applying uniformly distributed load of 5 bar. Finite element analysis is carried out to identify the potential design in obtaining optimum solution in designing ultimate stiffened plate. Result shows that the performance of stiffened square plate structure can be improved approximately by $80 \%$ in terms of tension and compression using topography optimization of finite element analysis.
\end{abstract}

\section{Introduction}

Finite element analysis (FEA) is originally initiated for solving a solid mechanics problems by using numerical method to calculate the responses of a structure to combination of applied load such as pressure and force to a support. All function used should satisfy the boundary conditions of the existing problems [1]. It is also considered as a practicable technique for computer solution of complex engineering problem. Apart of FEA, optimization is a solution to a problem to obtain an optimum function for a particular design [2]. Optimization techniques is now view as the tool of the utmost importance for engineering in many industries such as in aerospace, manufacturing, automotive and chemical industry. Optimizations techniques can be classified as design optimization which includes shape optimization [8], topological optimization [10], topography optimization [9] and sizing optimization [11]. In this research, topography optimization is used to optimize the structure of stiffened square plate. A stiffened square plate is widely used in industry especially in ship structure [3,4] and water tank base [5]. Stiffeners are used on a stiffened plate to resist highly directional loads while introduce multiple load paths that may provide protection against damage and crack growth under both compressive and tensile loads [12]. Ship hull structure received flexural compressive stress from water pressure [14], resulted

\footnotetext{
*Corresponding author: noor.eman91@gmail.com
} 
in instability of it's structure. This situation will lead to plate deformation as well as increase the stress and strain of the plate. This paper explains the structure analysis of stiffened square plate under uniformly distributed pressure of 5 bar and topography optimization as tools in optimizing the design of stiffened square plate through topographic analysis. The advantage of the stiffener is to increase bending stiffness of the plate with minimum additional material, which makes these structures highly desirable for out-ofplane loads and destabilizing compressive loads. Optimized stiffened plate in developing inspection and correction of stiffened plate in the ship plating and typical web frame of a tanker is obtained by using this element.

\section{Methodologies - modelling of stiffened plate}

The size of the basic stiffened plate model is $300 \mathrm{~mm} \times 300 \mathrm{~mm} \times 5 \mathrm{~mm}$ as shown in Fig. 1 . According to [13], a plate is considered as a thin plate structure if the ratio of width to length of the plate is maximum 0.1. Stainless steel which has elastic modulus of $210 \mathrm{GPa}$, tensile strength of $515 \mathrm{MPa}$ and yield strength of $207 \mathrm{MPa}$ is selected as material for the plate [6]. Topography analysis is carried out to obtain preliminary result in improving and optimizing plate performance [7]. The analysis is carried out by giving the uniformly distributed pressure of 5 bar to the square plate by using the inspire 2015 from Altair HyperWorks. The element size used for the analysis is obtained from calculation and graph convergence, which gives the value of $0.0060778 \mathrm{~m}$. Square mesh is choosing for this analysis because all of the models are in square shape. All 4 edges of the square plate are clamped.

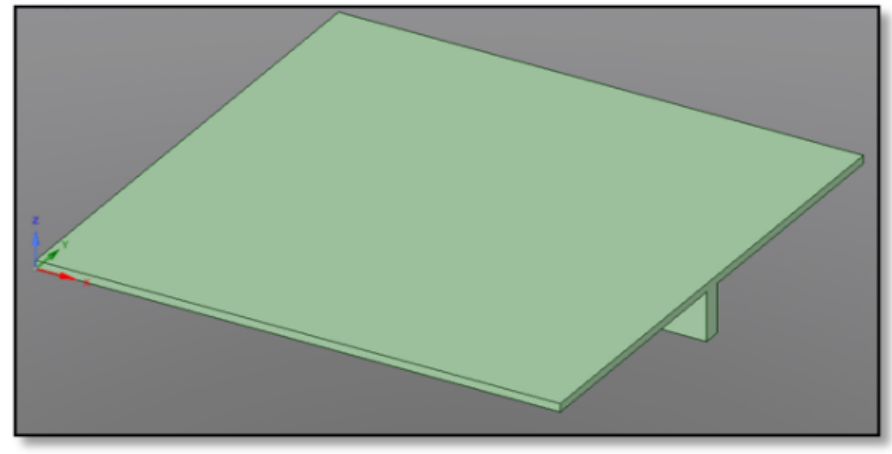

Fig. 1. Basic Model of Stiffened Plate

Optimization of stiffened square plate are carried out based on the preliminary analysis that obtained from basic model to ensure the stiffened square plate are at optimum performance.The parameters that will change is types of stiffeners on the square plate. There are four designs that have been considered including the regular optimization that is widely used in ship structure plating and typical web frame of a tanker. 


\section{Results and discussions}

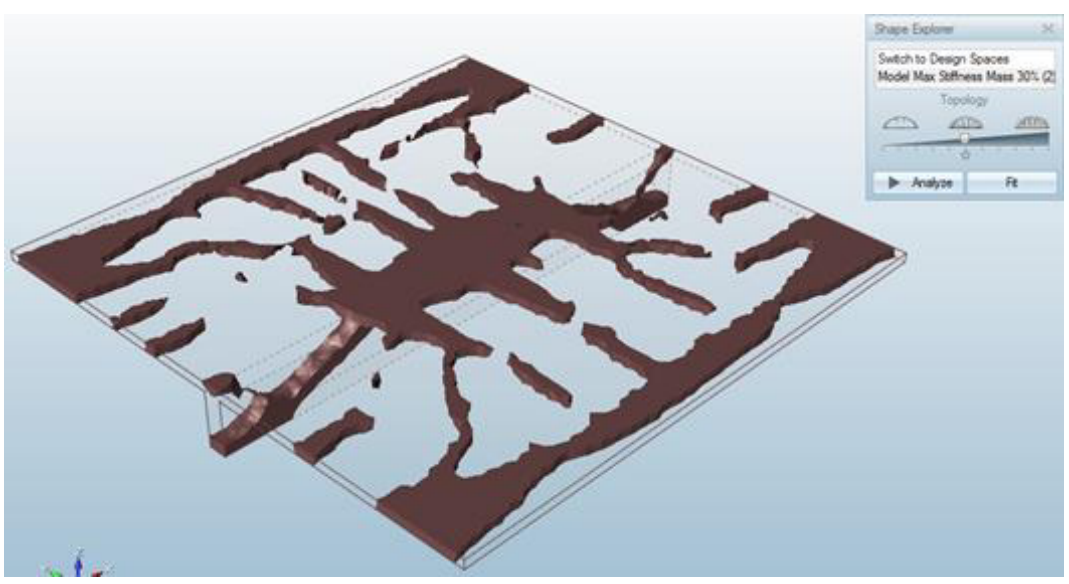

Fig. 2. Topography Analysis on Basic Model of Stiffened Plate

Fig. 2 shows stress contour for the basic model of stiffened plate. Dark color area shows critical section with maximum stress. Based on the result, stress concentration of deformation are located in the middle of the plate and at the fixed end that is not attached with stiffener. Colorless area shows area with minimum stress. Under the influence of the repeated stress, creep will happen at dark color area whereby plate becomes unstable and it leads to permanent plate deformation [15]. Therefore, stiffener must be present in supporting plate structure against load distribution in order to avoid brittle fracture. Four optimization designs are proposed in improving plate performance including regular optimization as shown by Fig. 3.

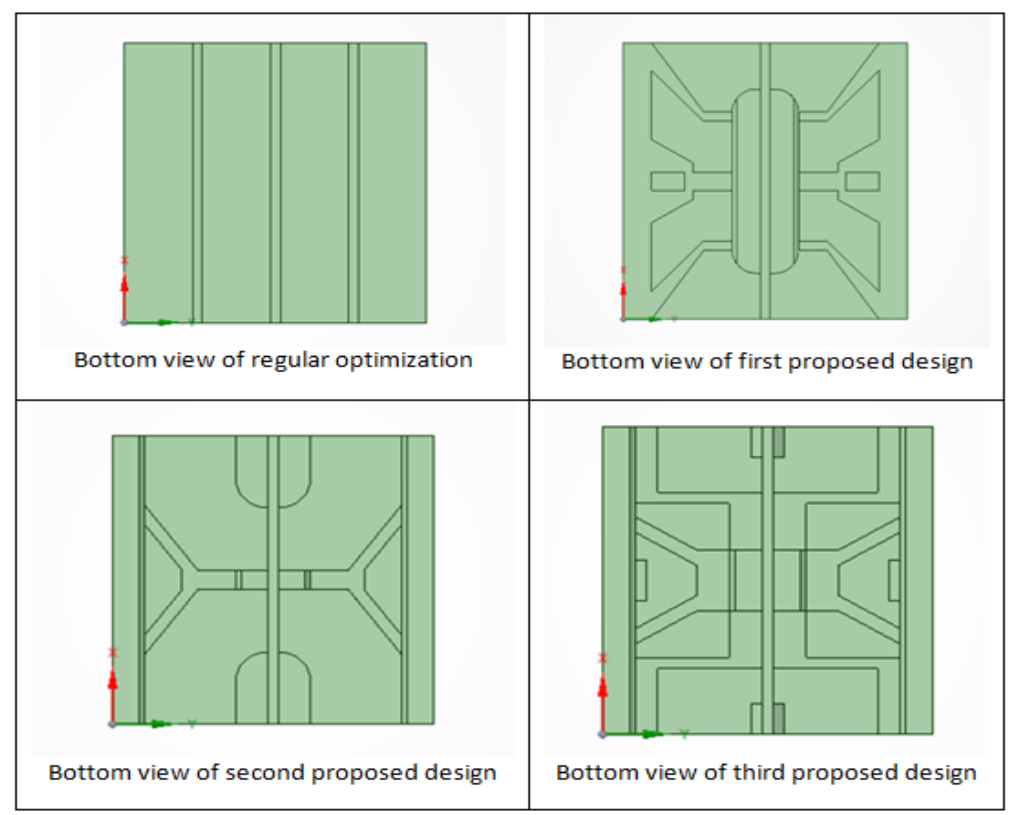

Fig. 3. Proposed Design of Stiffened Square Plate 


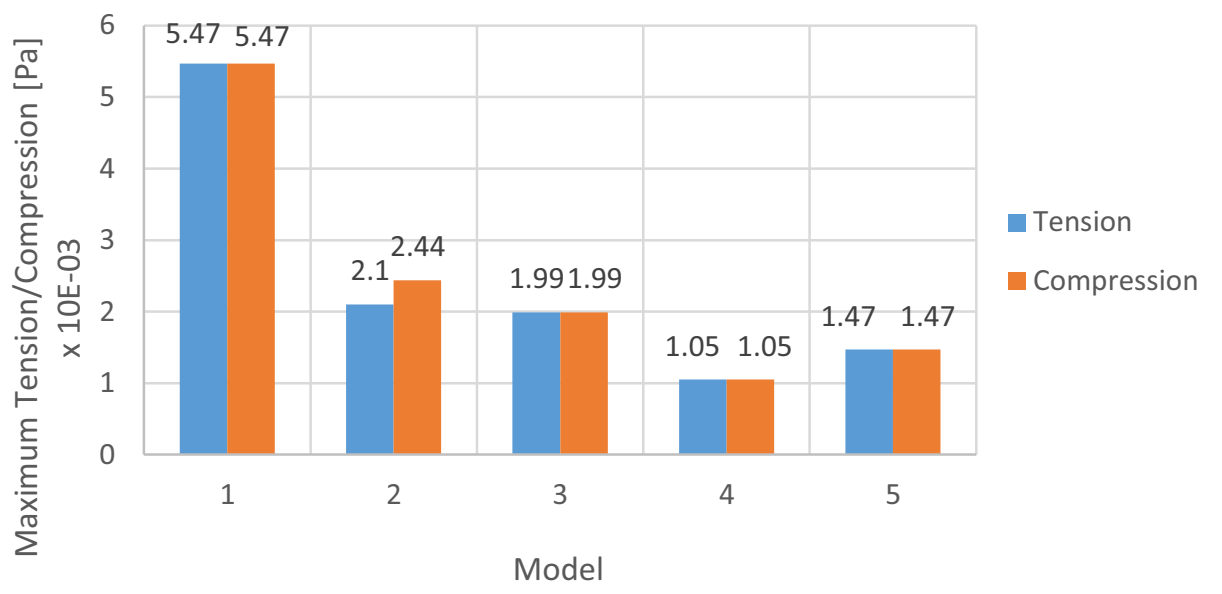

Fig. 4. Maximum Tension / Compression

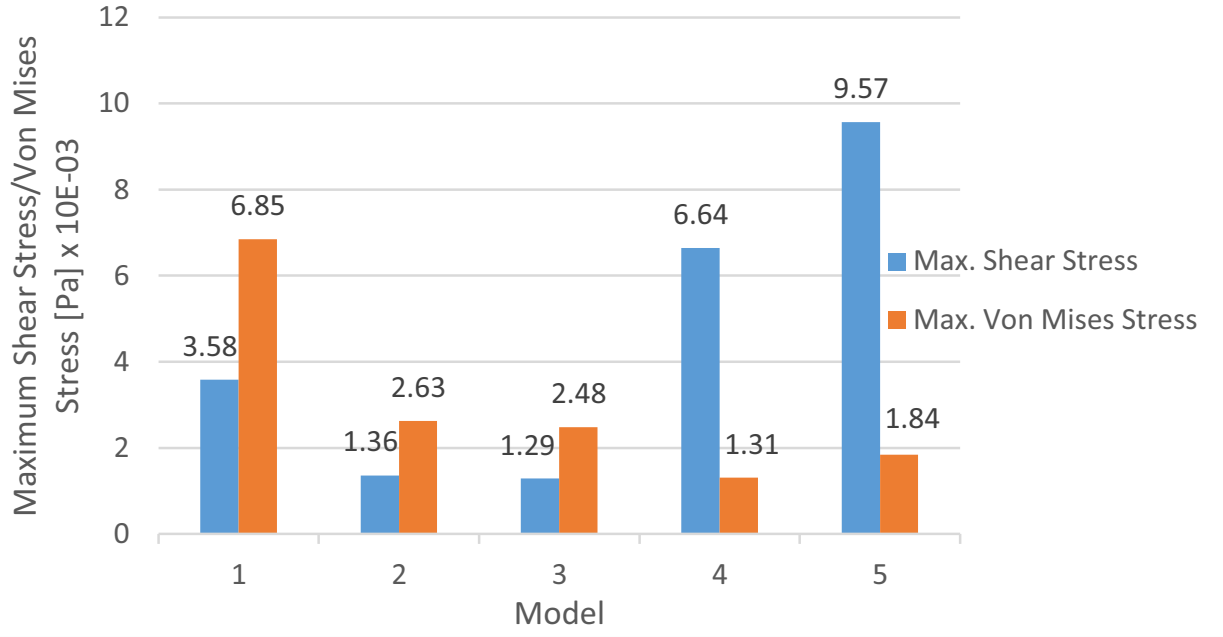

Fig. 5. Maximum Shear Stress / Von Mises Stress 


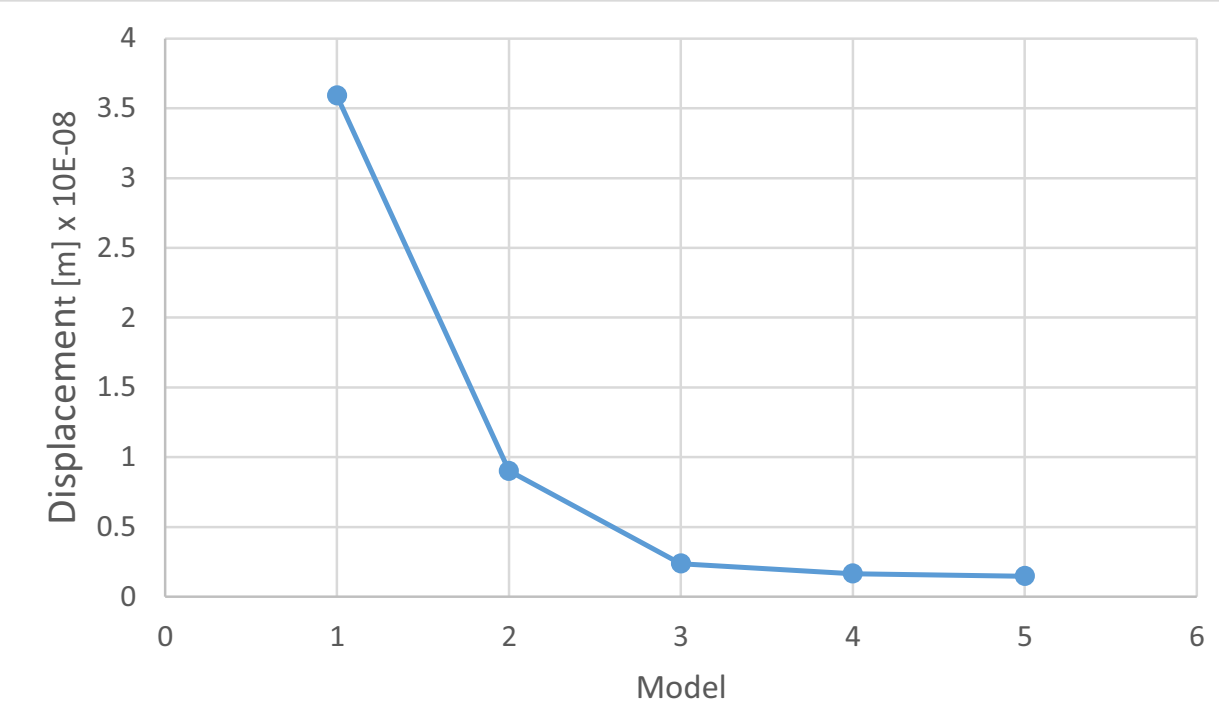

Fig. 6. Maximum Displacement

Fig. 6 shows that the displacement of stiffened plate is reduced from basic model $\left(3.59 \times 10^{-8} \mathrm{~m}\right)$ to regular optimization $\left(9.02 \times 10^{-9} \mathrm{~m}\right)$. The number decreased further for suggested design after topography optimization that are, $2.389 \times 10^{-9} \mathrm{~m}\left(1^{\text {st }}\right.$ optimization), $1.658 \times 10^{-9} \mathrm{~m}$ ( $2^{\text {nd }}$ optimization) and $1.489 \times 10^{-9} \mathrm{~m}$ respectively. It means, when the displacement is reduced, the bending that occurs on the stiffened plate which can lead to fracture will also be reduced. In terms of tension and compression in Fig. 4, results show that second optimization design is the best optimization with lowest value of $1.05 \times 10^{-3} \mathrm{~Pa}$. The results was reinforced by the maximum value of von Mises Stress in Fig. 5 that proved second optimization as the best optimization for the stiffened plate with the value of $1.31 \times 10^{-3} \mathrm{~Pa}$. Besides, second optimization has the lowest mass per diagram than other types of optimization. From the result in Table 1, second optimization can be considered as the best optimization in giving the best performance to the stiffened plate.

Other than using single type optimization, Belblidia et al has introduced in their work integrated design optimization by combining topology optimization and sizing optimization as suitable method in producing lightweight stiffened plate [16]. Thus, combination of topology optimization and topography optimization is the line of research arising from this work which could be continued.

\section{Conclusions}

Based on this research, it shows clearly that the stiffened square plate can be optimized and the performance of stiffened square plate can be improved using the topography optimization. The value of maximum displacement can be accepted for all design because it represents a very small number which can be ignored. However for maximum tension, maximum compression and maximum von Mises Stress, second design optimization represents the best design because it has the lowest value for these three properties.

The team would like to thank the Ministry of Higher Education (MOHE) and Universiti Technical Malaysia Melaka (UTeM) for the financial support in publishing this paper under grant PJP/2015/FTK(34C)S01459. 


\section{References}

1. O.C. Zienkiewicz, R.L. Taylor, David Fox, "The Finite element Method for Solid and Structural Mechanics", 7th Edition, Butterworth- Heineman Publisher (2014)

2. R. Ramkumar, V.R. Lenin, A. Krishnaraju, M. Senthilkumar, International Journal of Engineering Trends and Technology (IJETT), 21, 12 (2015)

3. H.W. Leheta, S.F. Badran, A.S. Alhanafi, Thin-Walled Structures, 94, 545 (2015)

4. Y.V. Satish Kumar, M. Mukhopadhyay, Applied Ocean Research, 22, 361 (2000)

5. A.S. Anumod, S. Harinarayanan, S.Usha, Int. J. Eng. Res. Ind. Appl., 47-54 (2015)

6. W.D. Callister, D.G. Rethwisch, Material Science and Engineering - An Introduction. 7th Edition, John Wiley \& Sons (2007)

7. Y. Liu, G. Yang, J. Lian, J. Mater. Process. Technol., 31, 327 (1992)

8. P. Plotnikov, J. Sokolowski, “Compressible Navier-Stokes Equation. Theory and Shape Optimization”, Springer, Basel (2012)

9. R. Chakravarty, Study of Topography Optimization on Automotive Body Structure. SAE Technical Paper. (2009)

10. L. Naesung, S. Kazuhiro, Journal of Mechanical Design, 127, 170, (2005)

11. F. Behrooz, A. Ali, Int. J. Solids Struct., 47, 2508 (2010)

12. E. Adel, Mech. Adv. Mater. Struct., 20, 764 (2013)

13. S. Timoschenko, S. Woinowsky-Krieger, Theory of Plates and Shells. McGraw-Hill Classic Textbook, $2^{\text {nd }}$ Edition, USA (1959)

14. Y. Okumoto, Y. Takeda, M. Mano, T. Okada, Design of Ship Hull Structures - A Practical Guide for Engineers. Springer-Verlag Berlin Heidelberg (2009)

15. W. Jiang, G. Jianming, C. Hu, T. Shandong, T. Shan Tung, Acta Metall. Sin., 43, 539 (2007)

16. F. Belblidia, S.M.B. Afonso, E. Hinton, G.C.R., Engineering Computations. 16, 934 (1999) 